\title{
Effect of Particle Size on the HDS Activity of Molybdenum Sulfide
}

\section{Carola Contreras, Fernanda Isquierdo, Pedro Pereira-Almao, and Carlos E. Scott}

Schulich School of Engineering, Department of Chemical and Petroleum Engineering, University of Calgary, 2500 University Drive NW, Calgary, AB, Canada T2N 1 N4

Correspondence should be addressed to Carlos E. Scott; scottc@ucalgary.ca

Received 21 June 2016; Accepted 14 November 2016

Academic Editor: Carlos R. Cabrera

Copyright ( 2016 Carola Contreras et al. This is an open access article distributed under the Creative Commons Attribution License, which permits unrestricted use, distribution, and reproduction in any medium, provided the original work is properly cited.

\begin{abstract}
More than half of the total world oil reserves are heavy oil, extra heavy oil, and bitumen; however their catalytic conversion to more valuable products is challenging. The use of submicronic particles or nanoparticles of catalysts suspended in the feedstock may be a viable alternative to the conversion of heavy oils at refinery level or downhole (in situ upgrading). In the present work, molybdenum sulfide $\left(\mathrm{MoS}_{2}\right)$ particles with varying diameters $(10000-10 \mathrm{~nm})$ were prepared using polyvinylpyrrolidone as capping agent. The prepared particles were characterized by DLS, TEM, XRD, and XPS and tested in the hydrodesulfurization (HDS) of a vacuum gas oil (VGO). A correlation between particle size and activity is presented. It was found that particles with diameters around $13 \mathrm{~nm}$ show double the HDS activity compared with the material with micrometric particle sizes (diameter $\approx 10,000 \mathrm{~nm}$ ).
\end{abstract}

\section{Introduction}

The depletion of light oils supplies along with the expected increase in energy demand has shifted the attention to the exploitation and conversion of heavy oils and heavy petroleum fractions. More than half of the total world oil reserves are heavy oil, extra heavy oil, and bitumen, with vast deposits in Canada (Alberta province) and Venezuela (Orinoco region). Even though catalytic hydroprocessing is a well-established process in the refining industry the conversion of such heavy oil fractions is challenging, from the catalytic point of view, due to metal sulfides and coke deposition in the pore mouth of the support in the commonly used $\mathrm{Ni}(\mathrm{Co}) \mathrm{Mo}(\mathrm{W}) /$ alumina catalysts, which leads to the reduction of the catalysts effective life. One alternative to avoid the problem posed by the use of supported porous catalysts is the application of ultradispersed catalysts, which are very small particles suspended in the feed to be processed [1-8]. Also, in situ (or downhole) processing has been proposed as a way of producing synthetic oils from heavy oils and bitumen in the reservoir, thus reducing energy demands for field hydroprocessing and decreasing emissions [9-11]. For this application the particle size of the catalyst should be as small as possible (preferably in the nanorange, i.e., $<100 \mathrm{~nm}$ ) in order to increase their efficiency and to be able to navigate in the porous media without causing any plugging or impairment of the reservoir [12].

$\mathrm{MoS}_{2}$ is the base of hydroprocessing catalysts; however there are no reports on the effect of the particle size on the HDS activity for real feeds using unsupported (bulk) $\mathrm{MoS}_{2}$. Kuriki et al. [13] obtained particles of different diameters (2600-40 $\mathrm{nm}$ ) by milling commercial $\mathrm{MoS}_{2}$ and tested them in the hydrogenation of 1-methylnaphthalene. From the data presented it can be inferred that smaller particles possess higher specific activity but a correlation between conversion and particle size is not presented.

Even though smaller particles are expected to have higher activity, this may not always be the case [14]. Also, the kind of feed and the morphology of the particles could have an important effect on their activity [15].

Preparation of $\mathrm{MoS}_{2}$ particles has been performed by different methodologies including the sulfidation of oxides $[16,17]$, the decomposition of precursors [18], ultrasonic irradiation [19-21], the use of emulsions [22-27], or using Layered Double Hydroxide (LDH) as hard template [28]. Most of these methodologies do not produce nanoparticles or 
TABLE 1: Vacuum gas oil (VGO) characteristics.

Viscosity/cP at $298 \mathrm{~K}$

Sulfur content/wt\%

Boiling point $/ \mathrm{K}$

492 to 873

allow controlling the particle diameter. Additionally, in some cases, the yields obtained from such preparations are very low and further testing the activity of the particles prepared is not possible.

Synthesis of nanoparticles assisted by capping agents has been reported in the literature for the preparation of defined shapes and sizes of nanostructures, such as nanorods and nanowires [29-31]. The preparation of particles coated with a thin protective polymer layer is a good approach since they are more stable against aggregation (due to the large decrease in surface energy). This is important since it is known that when approaching the nanometric range the high surface energy of inorganic nanoparticles makes them very unstable, prone to undergo chemical reactions with the environment and also to self-aggregate [29].

In the present work, $\mathrm{MoS}_{2}$ nanoparticles with different diameters were prepared in presence of polyvinylpyrrolidone (PVP) as capping agent using a simple methodology suitable for preparing homogeneous nanoparticles with different diameters and reasonable quantities.

The particles were characterized by Dynamic Light Scattering (DLS), Transmission Electron Microscopy (TEM), $\mathrm{X}$-ray Diffraction (XRD), and X-ray Photoelectron Spectroscopy (XPS). The hydrodesulfurization (HDS) of a vacuum gas oil (VGO) in a batch reactor using $3.44 \mathrm{MPa}$ of hydrogen and $653 \mathrm{~K}$ was used for catalytic activity determinations.

\section{Materials and Methods}

2.1. Materials. Crystalline ammonium tetrathiomolybdate (99.97\%) and polyvinylpyrrolidone (99\%) were obtained from Aldrich and used without any further treatment. Sulfuric acid (98\%) and methanol of analytical grade were also used in the preparations of the particles. A vacuum gas oil (VGO), whose characteristics are shown in Table 1, was used as feedstock for the hydrodesulfurization (HDS) reactions.

2.2. Particles Preparation. The preparation of the $\mathrm{MoS}_{2}$ was made based on a methodology adapted from the one reported by Amma and collaborators [31] for the preparation of cadmium sulfides nanoparticles using different capping organic agents. A simple preparation methodology was developed by precipitating $\mathrm{MoS}_{3}$ (which is converted to $\mathrm{MoS}_{2}$ by thermal treatment), acidifying a solution of ammonium tetrathiomolybdate (ATTM) and the capping agent according to the following chemical reaction:

$$
\mathrm{MoS}_{4}{ }^{2-}+2 \mathrm{H}^{+} \longrightarrow \mathrm{MoS}_{3}+\mathrm{H}_{2} \mathrm{~S}
$$

Thus, to $30 \mathrm{~cm}^{3}$ of a $0.01 \mathrm{M}$ solution of ATTM in methanol: water $(1: 1 ; \mathrm{v} / \mathrm{v}), 15 \mathrm{~cm}^{3}$ of PVP in methanol solution $(0.5,0.1,0.02$, or $0.01 \mathrm{mM})$ was added and mixed well. Then $0.5 \mathrm{~cm}^{3}$ of a $0.5 \mathrm{M}$ sulfuric acid solution was added drop by drop with intense agitation, which immediately turned the color of the solution from light orange to dark brown. The solutions were then centrifuged at $10000 \mathrm{rpm}$ for periods of 20 minutes and washed three times with warm water and twice with methanol to eliminate (as much as possible) any remaining capping agent from the surface. The separation of the solids prepared using PVP concentration of $0.5,0.1$, and $0.02 \mathrm{mM}$ was very difficult and the amount of solid obtained was low representing a yield of around $50 \%$. For the other two preparations ( 0.01 and $0 \mathrm{mM}$ of PVP) the separation was easy and the yield was about $75 \%$. Finally, the obtained solids were air and vacuum dried (at $353 \mathrm{~K}$ ) overnight to produce the as-prepared particles.

2.3. Particle Characterization. The size of the particles was determined by DLS using a Zetasizer Nano S (Malvern Instruments) equipped with a $4.0 \mathrm{~mW}$ He-Ne laser $(633 \mathrm{~nm})$ operated at an angle of $173^{\circ}$ and a temperature of $298 \mathrm{~K}$ to obtain the average particle diameter (Z-Ave) of the suspended particles. The particles were redispersed in acetone and sonicated in a laboratory bath for 15 minutes prior to the size determination.

TEM images were obtained on a HITACHI 7650 microscope (point-to-point resolution using an accelerating voltage of $80 \mathrm{kV}$ ). Solid samples (a tip of a small spatula) were added to a vial containing $3 \mathrm{~cm}^{3}$ of a 1:1 ethanol/water mixture and sonicated in a bath until the solution appeared homogeneous. Then one drop of the suspension was placed on the carbon side of a copper grid and let to dry in a fume hood. Once dried the samples were taken to the microscope for analysis.

XRD patterns were obtained with a Rigaku X-ray diffractometer (Model Ultima III) over the 2 theta range of 5 to 90 degrees, scanning speed of 0.2 degrees/second, and a step size of 0.02 degrees (2 theta) with $\mathrm{Cu} \mathrm{K} \alpha$ radiation and $40 \mathrm{KV}$. The XRD patterns were referenced to the powder diffraction files (International Centre for Powder Diffraction PDF 2005) using the pattern processing analysis software JADE from Materials Data Inc.

A PHI VersaProbe 5000-XPS was used to record XPS spectra. The spectra were taken on samples pressed on double sided tape, using monochromatic $\mathrm{Al}$ source, $1486.6 \mathrm{eV}$, with $49.3 \mathrm{~W}$ of power and beam diameter of $200.0 \mu \mathrm{m}$. Double neutralization, that is, a low energy electron beam and low energy $\mathrm{Ar}^{+}$beam, was used during spectrum taking to avoid nonuniform charging. Binding energies relative to $\mathrm{Cl}_{\mathrm{S}}$ at $284.8 \mathrm{eV}$ are reported. Data analysis was performed using MultiPak software developed by Physical Electronics and provided with the XPS instrument.

2.4. Catalytic Activity. The particles produced were tested for the HDS of a VGO in a batch Parr reactor under $3.44 \mathrm{MPa}$ of hydrogen at $653 \mathrm{~K}$ during 6 hours. The reactor was first loaded with the mixture of particles $(\approx 0.0580 \mathrm{~g}$.) suspended in VGO $(\approx 20.000$ g.). The reactor was tested for leaks and purge with hydrogen, before heating was started at $20 \mathrm{~K} \mathrm{~min}^{-1}$ and the stirring set at $500 \mathrm{rpm}$. Hydrogen inlet was kept open during 
TABLE 2: Particle diameter determined by DSL.

\begin{tabular}{lcc}
\hline Sample & $\begin{array}{c}\text { Capping agent } \\
\text { concentration }(\mathrm{mM})\end{array}$ & Diameter (nm) \\
\hline $\mathrm{MoS}_{x}-\mathrm{PVP}(1.0)$ & 1.0 & $10 \pm 1$ \\
$\mathrm{MoS}_{x}-\mathrm{PVP}(0.5)$ & 0.5 & $13 \pm 1$ \\
$\mathrm{MoS}_{x}-\mathrm{PVP}(0.1)$ & 0.1 & $15 \pm 2$ \\
$\operatorname{MoS}_{x}-\mathrm{PVP}(0.02)$ & 0.02 & $136 \pm 32$ \\
$\operatorname{MoS}_{x}-\mathrm{PVP}(0.01)$ & 0.01 & $400 \pm 130$ \\
$\operatorname{MoS}_{x}-\mathrm{PVP}(0)$ & 0 & $10200 \pm 2000^{*}$ \\
\hline
\end{tabular}

* Determined by light microscopy.

the test in order to avoid pressure dropping due to hydrogen consumption. Once the reaction time was completed, the reactor was cooled down and opened and the liquid products were separated from the catalysts by centrifugation. The liquid products were dissolved in toluene and the sulfur content, of the original VGO and reaction products, was determined on an Antek 9000 NS elemental analyzer.

\section{Results and Discussion}

Particle sizes obtained by DLS, for the as-prepared solids, are presented in Table 2 along with the corresponding standard deviation. Solid are named using the following nomenclature: $\mathrm{MoS}_{x}-\mathrm{PVP}(\mathrm{X})$, where value in parenthesis indicates the concentration of PVP used in the preparation. Each value is the average of 3 preparations except for the solid $\mathrm{MoS}_{x}-\mathrm{PVP}(0.01)$, where only particles from two different preparations were measured, and the solid made without PVP from which only one preparation was done. The sample with no PVP was obtained following the same methodology as the samples with PVP, but with no addition of the capping agent solution.

As can be seen, particles with diameters as small as $10 \mathrm{~nm}$ were produced. The use of PVP concentrations higher than $0.1 \mathrm{mM}$ does not produce significant changes in the particle size (see Table 2). A similar effect (i.e., increasing the concentration of the capping agent produces only minor changes in particle diameter) has been reported for the preparation of CdS nanoparticles using glucose as capping agent [32] and $\mathrm{ZnS}$ with mercaptoethanol [33].

The solids $\operatorname{MoS}_{x}-\mathrm{PVP}(0.5), \mathrm{MoS}_{x}-\mathrm{PVP}(0.02), \mathrm{MoS}_{x^{-}}$ $\operatorname{PVP}(0.01)$, and $\mathrm{MoS}_{x}-\mathrm{PVP}(0)$ were chosen for the preparation of the particles to study the catalytic activity dependence on particle size.

In order to confirm the particle size obtained by DLS, TEM analysis was also performed (however a statistical analysis was not done) and micrographs of $\mathrm{MoS}_{x}-\mathrm{PVP}(0.5)$, $\mathrm{MoS}_{x}-\mathrm{PVP}(0.02)$, and $\mathrm{MoS}_{x}-\mathrm{PVP}(0.01)$ are shown in Figure 1 , where small spherical particles with diameters around $17 \mathrm{~nm}$ and $118 \mathrm{~nm}$ are observed for $\operatorname{MoS}_{x}-\mathrm{PVP}(0.5)$ and $\mathrm{MoS}_{x}-\mathrm{PVP}(0.02)$, respectively. These values estimated by TEM are in good agreement with those obtained by DLS (see Table 2). For the solid $\operatorname{MoS}_{x}-\operatorname{PVP}(0.01)$ particles with the shape of small rods were obtained. Why the produce particles presented that shape is not clear. The rods are around
$366 \mathrm{~nm}$ long and $102 \mathrm{~nm}$ thick. The solid prepared without the use of the capping agent was observed by light microscopy (Figure 2), and very large particles with diameters of around $10 \mu \mathrm{m}$, forming agglomerates, were observed.

The particles before reaction were also analyzed by XRD (Figure 3). The distinctive amorphous pattern of $\mathrm{MoS}_{3}$ [34], which is the expected product according to reaction (I), is clearly observed for the samples prepared with PVP.

XRD patterns for the solids after reaction (Figure 3) show very broad lines characteristic of amorphous materials, consistent with the low particle diameter observed by DLS and TEM. The (002) basal plane peaks (line at around 15 $2 \theta^{\circ}$ ) show very low intensity indicating low or no stacking at all and highly disordered packing of $\mathrm{MoS}_{2}$ slabs. Other broad peaks at higher angle $\left(2 \theta>30^{\circ}\right)$, also characteristic of $\mathrm{MoS}_{2}$, are observed. TEM image obtained for the $\mathrm{MoS}_{x^{-}}$ $\operatorname{PVP}(0.02)$ after reaction (not shown) shows the solid to be mainly composed of single slabs, characteristic of the $\mathrm{MoS}_{2}$ structure, in a much disorganized pattern.

According to the geometrical model proposed by Kasztelan et al. [35], the active site on a supported active phase is a distribution of very small two-dimensional patches of $\mathrm{MoS}_{2}$. Eijsbouts et al. [36] reported a linear correlation between the hydrodenitrogenation activity (HDN) and the number of accessible corners and edges in the $\mathrm{MoS}_{2}$ for supported $\mathrm{NiMo} / \mathrm{Al}_{2} \mathrm{O}_{3}$ commercial catalysts. Also, it has been suggested [37] that the activity of the particles is related not only to the amount of molybdenum atoms found at the edges, where sulfur vacancies can be formed easier, but also to the stacking number. Those results seem to indicate that very small $(15-10 \mathrm{~nm})$ nonstacked nanoparticles, like the ones obtained in this work, with a higher density of edge sites should produce higher HDS activity.

X-ray photoelectron spectra are shown in Figures 4 and 5. $\mathrm{MoS}_{3}$ synthesized by acidification of ATTM [34] solution is also included. This sample was prepared in order to compare the corresponding binding energies with those of the precipitated nanoparticles before reaction since the binding energy values reported in the literature vary widely [37-47].

Figure 4(a) shows the Mo3d signal for the precipitated $\mathrm{MoS}_{3}$. A main doublet located at $228.77 \mathrm{eV}\left(\mathrm{Mo}_{5 / 2}\right)$ and $232.00 \mathrm{eV}\left(\mathrm{Mo}_{3 / 2}\right)$ that should correspond to $\mathrm{MoS}_{3}$ is observed, and the binding energies are close to the ones reported by Stevens and Edmonds [43] and Vrubel et al. [46] for this compound. Another less intense doublet is observed at $230.13 \mathrm{eV}$ for $\mathrm{Mo}_{5 / 2}$ and $233.54 \mathrm{eV}$ for $\mathrm{Mo}_{5} \mathrm{~d}_{3 / 2}$ which can be assigned to Mo oxysulfide phase $\left(\mathrm{MoO}_{x} \mathrm{~S}_{y}\right)$ [39] or to $\mathrm{Mo}_{2} \mathrm{~S}_{5}[8,44] . \mathrm{Mo}_{2} \mathrm{~S}_{5}$ could have been formed while the sample was dried at $353 \mathrm{~K}$ under vacuum overnight. Finally, a third minor doublet $\left(231.81 \mathrm{eV}\right.$ for $\mathrm{Mo}_{5 / 2}$ and $235.09 \mathrm{eV}$ for $\mathrm{Mo}_{3 / 2}$ ) can be assigned to MoVI oxide phase. Bands at lower binding energy that correspond to S2s photoemission with contribution for $\mathrm{S}^{2-}$ and $\mathrm{S}_{2}{ }^{2-}$ at 226.13 and 227.40, respectively, are also obtained.

The high resolution X-ray photoelectron spectrum for the sample $\mathrm{MoS}_{x}-\mathrm{PVP}(0.5)$ before reaction (Figure 4(b)) also shows three $3 \mathrm{~d}_{5 / 2}-3 \mathrm{~d}_{3 / 2}$ spin-orbit coupling signals. Similar doublets at about the same binding energies as the ones 


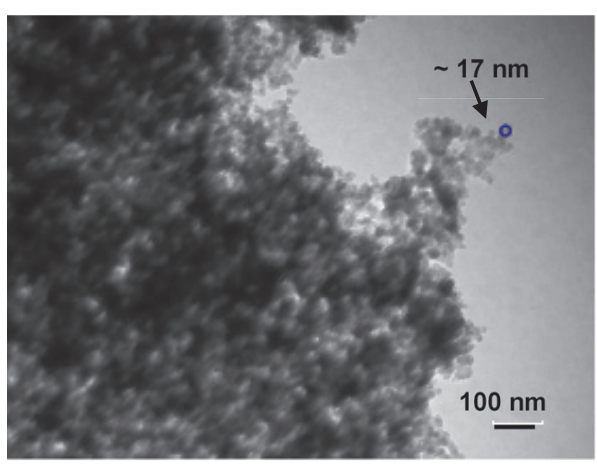

(a)

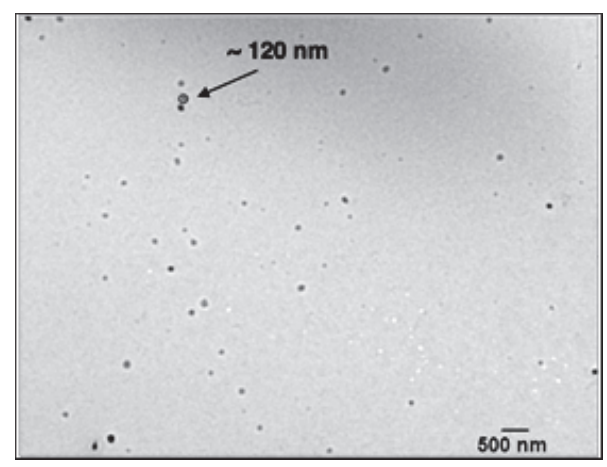

(b)

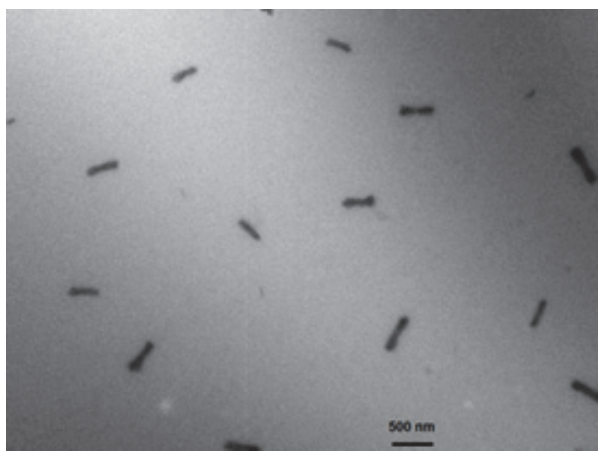

(c)

Figure 1: TEM micrograph of particles before reaction (a) $\operatorname{MoS}_{x}-\mathrm{PVP}(0.5)$, (b) $\operatorname{MoS}_{x}-\mathrm{PVP}(0.02)$, and (c) $\operatorname{MoS}_{x}-\mathrm{PVP}(0.01)$.

TABLE 3: XPS parameters and assignments for $\mathrm{MoS}_{3}$ and $\mathrm{MoS}_{x}-\mathrm{PVP}(0.5)$ before and after VGO HDS reaction.

\begin{tabular}{|c|c|c|c|c|c|c|c|}
\hline Sample & Mo3d signal $(\mathrm{eV})$ & Assignment & $\%$ (at.) & S2p signal $(e V)$ & Assignment & $\%$ (at.) & S/Mo ratio $^{\mathrm{a}}$ \\
\hline \multirow{3}{*}{$\mathrm{MoS}_{3}$} & $228.8-232.0$ & $\mathrm{MoS}_{3}$ & 79 & $161.5-162.6$ & $\mathrm{~S}^{2-}$ & 58 & \multirow{3}{*}{2.90} \\
\hline & $230.1-233.5$ & $\mathrm{MoO}_{x} \mathrm{~S}_{y}$ or $\mathrm{Mo}_{2} \mathrm{~S}_{5}$ & 11 & $162.68-163.86$ & $\mathrm{~S}_{2}{ }^{2-}$ & 41 & \\
\hline & $231.8-235.1$ & $\mathrm{MoO}_{3}$ & 10 & 168.27 & $\mathrm{SO}_{4}{ }^{2-}$ & 1 & \\
\hline $\mathrm{MoS}_{x}-\mathrm{PVP}(0.5)$ & $228.9-232.1$ & $\mathrm{MoS}_{3}$ & 57 & $161.6-162.8$ & $S^{2-}$ & 45 & \multirow{3}{*}{2.97} \\
\hline \multirow{2}{*}{ Before reaction } & $230.1-233.4$ & $\mathrm{MoS}_{x} S_{y}$ or $\mathrm{Mo}_{2} \mathrm{~S}_{5}$ & 38 & $162.9-164.1$ & $\mathrm{~S}_{2}{ }^{2-}$ & 50 & \\
\hline & 231.9-235.4 & $\mathrm{MoO}_{3}$ & 5 & 168.2 & $\mathrm{SO}_{4}{ }^{2-}$ & 5 & \\
\hline $\mathrm{MoS}_{x}-\mathrm{PVP}(0.5)$ & $229.5-232.7$ & $\mathrm{MoS}_{2}$ & 94 & $162.4-163.6$ & $\mathrm{~S}^{2-}$ & 82 & \multirow{3}{*}{1.88} \\
\hline \multirow{2}{*}{ After reaction } & $233.3-236.5$ & $\mathrm{MoO}_{3}$ & 6 & $163.5-164.8$ & $\mathrm{~S}_{2}{ }^{2-}$ & 13 & \\
\hline & & & & 168.7 & $\mathrm{SO}_{4}{ }^{2-}$ & 5 & \\
\hline
\end{tabular}

a: atomic\% S/atomic\% Mo, both, are determined using the sensitivity factor provided by the MultiPacK software.

obtained for $\mathrm{MoS}_{3}$ are seen (see Table 3); however, the signal due to $\mathrm{MoO}_{x} \mathrm{~S}_{y}$ or $\mathrm{Mo}_{2} \mathrm{~S}_{5}\left(230.11 \mathrm{eV}\right.$ for $\mathrm{Mo}_{5 / 2}$ and $233.39 \mathrm{eV}$ for $\mathrm{Mo}_{3 / 2}$ ) is more intense in this case, suggesting that the prepared $\mathrm{MoS}_{3}$ nanoparticles are less pure than the ones prepared by precipitation. These results indicate that the nanoparticles, before reaction, are mainly constituted by $\mathrm{MoS}_{3}$, which is also supported by the XRD results (Figure 3). The third spin-orbit doublet for Mo3d in Figure 4(b) (231.93 eV for Mo3d $\mathrm{d}_{5 / 2}$ and $235.13 \mathrm{eV}$ for $\left.\mathrm{Mo3d}_{3 / 2}\right)$ may correspond to $\mathrm{MoO}_{3}$ due to partial oxidation of the sample during manipulation.

The spectrum for the sample after reaction has a simpler structure than the Mo3d signal of the one before reaction, showing a couple of $\mathrm{Mo}_{5 / 2-3 / 2}$ doublets. The first one has binding energy values of 229.52 and $232.66 \mathrm{eV}$, characteristic of $\mathrm{MoS}_{2}$ [48], and a minor second doublet assigned to $\mathrm{MoO}_{3}$, possibly formed as a result of sample handling. Also signal at $226.8 \mathrm{eV}$, which could be assigned to S2s for $\mathrm{MoS}_{2}$, is observed.

Figure 5(a) shows the XPS S2p signal for $\mathrm{MoS}_{3}$. Two doublets corresponding to the $S 2 p_{3 / 2}$ and $S 2 p_{1 / 2}$, are observed. The first one with the $2 \mathrm{p}_{3 / 2}$ peak centered at $161.45 \mathrm{eV}$ can be assigned to $\mathrm{S}^{2-}$, and the second one with a binding energy of $162.68 \mathrm{eV}$ can be attributed to polysulfide $\left(\mathrm{S}_{2}{ }^{2-}\right)$. The first signal shows higher intensity and the ratio $\left(\mathrm{S}^{2-}\right) /\left(\mathrm{S}_{2}{ }^{2-}\right)$ is 1.4 . Similar signals have been reported in the literature for $\mathrm{MoS}_{3}$ 


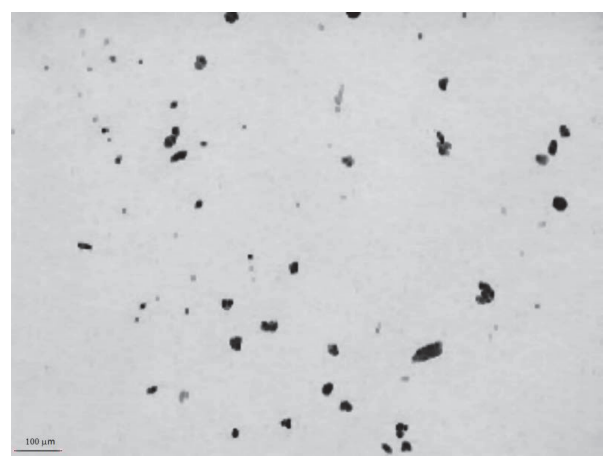

FiguRE 2: Image of $\mathrm{MoS}_{x}-\mathrm{PVP}(0)$ obtained with light microscope.

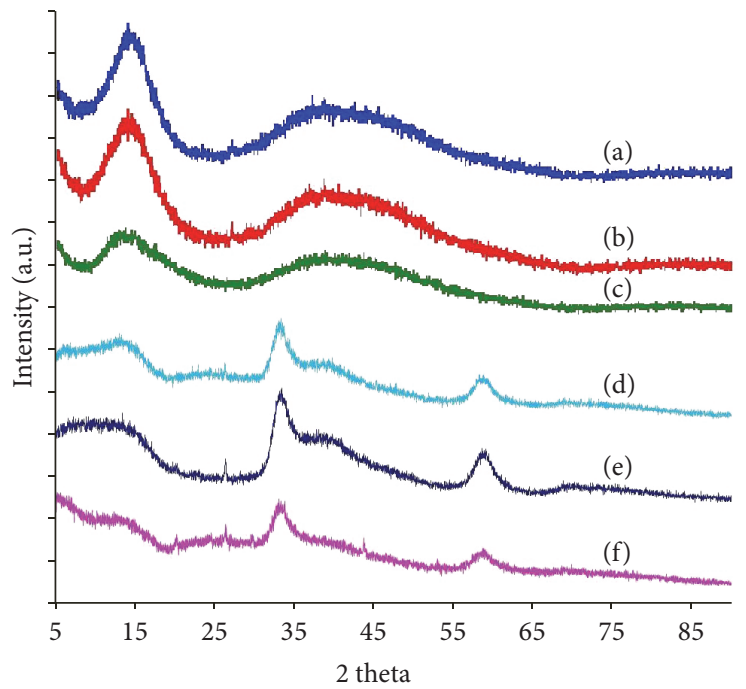

Figure 3: X-ray Diffraction patterns of catalysts. Freshly prepared solids: (a) $\operatorname{MoS}_{x}-\mathrm{PVP}(0.01)$; (b) $\operatorname{MoS}_{x}-\mathrm{PVP}(0.02)$; (c) MoS $-\mathrm{PVP}(0.5)$. Solids after VGO HDS reaction: (d) $\operatorname{MoS}_{x}-\mathrm{PVP}(0.01)$; (e) $\operatorname{MoS}_{x}-\mathrm{PVP}(0.02)$; (f) $\mathrm{MoS}_{x}-\mathrm{PVP}(0.5)$.

with $\left(\mathrm{S}^{2-}\right) /\left(\mathrm{S}_{2}{ }^{2-}\right)$ ratios from 0.5 to $2.4[39-43,46]$. There is also a small signal at higher binding energy which can be due to $\mathrm{SO}^{4-}$ formed by oxidation of the sample during manipulation.

For the solids before reaction (Figure 5(b)) two $\mathrm{S} 2 \mathrm{p}_{3 / 2}{ }^{-}$ $\mathrm{S} 2 \mathrm{p}_{1 / 2}$ are also observed with similar binding energies; however, the $\left(\mathrm{S}^{2-}\right) /\left(\mathrm{S}_{2}{ }^{2-}\right)$ is 0.88 and the difference could be due to the presence of some other sulfides or oxysulfides as evidenced in the Mo3d spectrum. After reaction, the solid shows S2p spectrum with one main doublet characteristic of $\mathrm{S}^{2-}$ in $\mathrm{MoS}_{2}$ with another small one, possibly due to impurities.

Table 3 presents a summary of the XPS binding energies for both samples and the assignment for the Mo3d and S2p signals. It is important to say that the $\mathrm{S} / \mathrm{Mo}$ ratio of 1.88 for sample after reaction is similar to previously reported S/Mo ratios for bulk $\mathrm{MoS}_{2}$ [37], while the ratio for the sample before reaction is 2.97 , which additionally supports the presence of $\mathrm{MoS}_{3}$.

From all the characterization shown, it is clear that during the reaction almost all (if not all) Mo is converted to $\mathrm{MoS}_{2}$. The formation of $\mathrm{MoS}_{2}$ from an intermediate $\mathrm{MoS}_{3}$ phase has
TABLE 4: $\operatorname{MoS}_{x}$ particle diameter and HDS conversion.

\begin{tabular}{lcc}
\hline Catalyst & Particle size $(\mathrm{nm})$ & HDS\% \\
\hline $\operatorname{MoS}_{x}-\operatorname{PVP}(0.5)$ & $13 \pm 1$ & 42 \\
$\mathrm{MoS}_{x}-\operatorname{PVP}(0.02)$ & $136 \pm 32$ & 28 \\
$\operatorname{MoS}_{x}-\operatorname{PVP}(0.01)$ & $400 \pm 130$ & 30 \\
$\operatorname{MoS}_{x}-\operatorname{PVP}(0)$ & $10200 \pm 2000$ & 18 \\
\hline
\end{tabular}

been reported to easily happens when $\mathrm{MoS}_{3}$ is heated above $623 \mathrm{~K}$ [29]. The XPS and XRD results support the formation of $\mathrm{MoS}_{2}$ on sample $\mathrm{MoS}_{x}-\mathrm{PVP}(0.5)$ after the reaction, which was performed at $653 \mathrm{~K}$.

The catalytic activity of the particles produced is shown in Table 4.

Important differences in the activity of these catalytic particles are observed in the HDS. A trend can be observed for the HDS activity of the solids with respect to the particle diameter (see Figure 6). The $\operatorname{MoS}_{x}-\operatorname{PVP}(0.5)$ solid with the smallest particle size is the one showing highest HDS conversion. The higher activity of the smaller particles could 


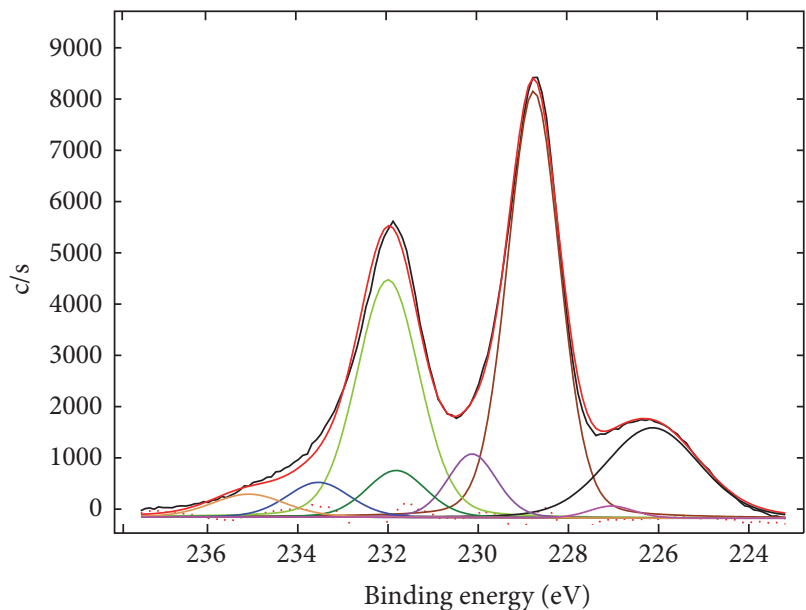

(a)

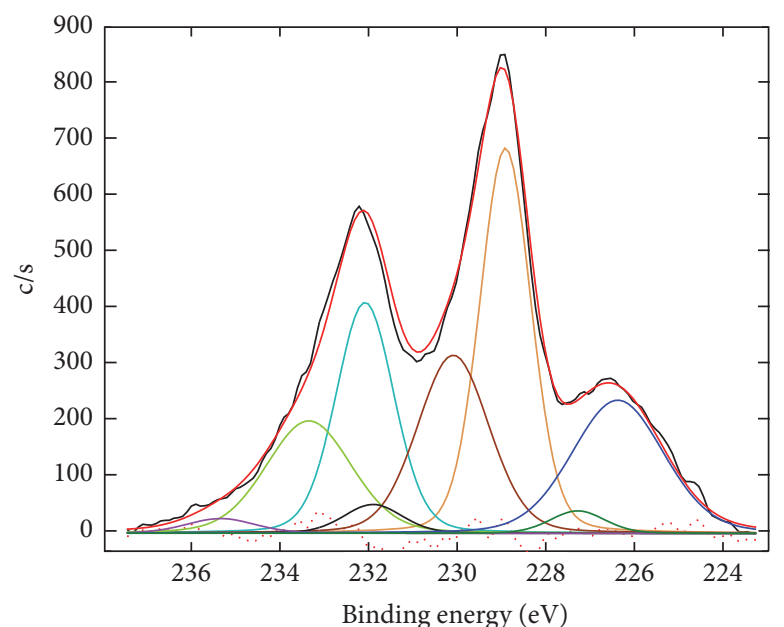

(b)

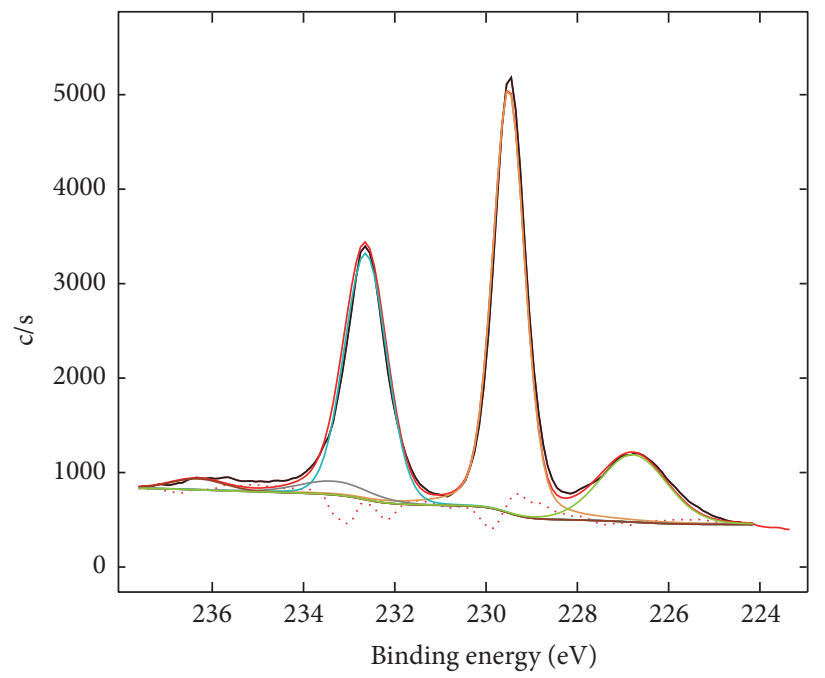

(c)

FIGURE 4: Fitted Mo3d XPS spectra of $\mathrm{MoS}_{3}$ (a) and $\mathrm{MoS}_{x}-\mathrm{PVP}(0.5)$ before reaction (b) and after reaction (c).

be the result of an increase in the number of available surface atoms located at the edges of the molybdenum sulfide clusters which have been proposed to be the active sites for HDS [35]. Figure 6 presents a plot of HDS conversion versus the particle diameter (in logarithmic scale) where a clear trend can be observed; however $\mathrm{MoS}_{x}-\mathrm{PVP}(0.02)$ and $\mathrm{MoS}_{x}-\mathrm{PVP}(0.01)$ show similar conversions. This effect might be due to the different morphology evidenced by TEM for these two materials. In fact, it has been reported that the morphology of $\mathrm{MoS}_{2}$ nanoparticles can lead to variations in the hydroconversion of vacuum residue [15]. Molybdenum sulfide particles obtained with diameters in the order of $13 \mathrm{~nm}$ show double the HDS conversion compared with the material prepared without addition of capping agent.

\section{Conclusions}

The present study shows the feasibility of preparing molybdenum sulfide nanoparticles with controlled diameters from 10 to $400 \mathrm{~nm}$ and very low stacking, as evidence by DLS, SEM, TEM, and XRD.

A trend was observed for the relationship between particle size and HDS conversion. For particles with diameters around $13 \mathrm{~nm}$, the \% of HDS was double that of bulk molybdenum sulfide and also significantly higher when compared with particles with diameters around 100-400 $\mathrm{nm}$.

\section{Competing Interests}

The authors declare that they have no competing interests.

\section{Acknowledgments}

The authors want to acknowledge the Natural Sciences and Engineering Research Council of Canada (NSERC), Nexen-CNOOC Ltd., and Alberta Innovates-Energy and Environment Solutions (AIEES) for the financial support 


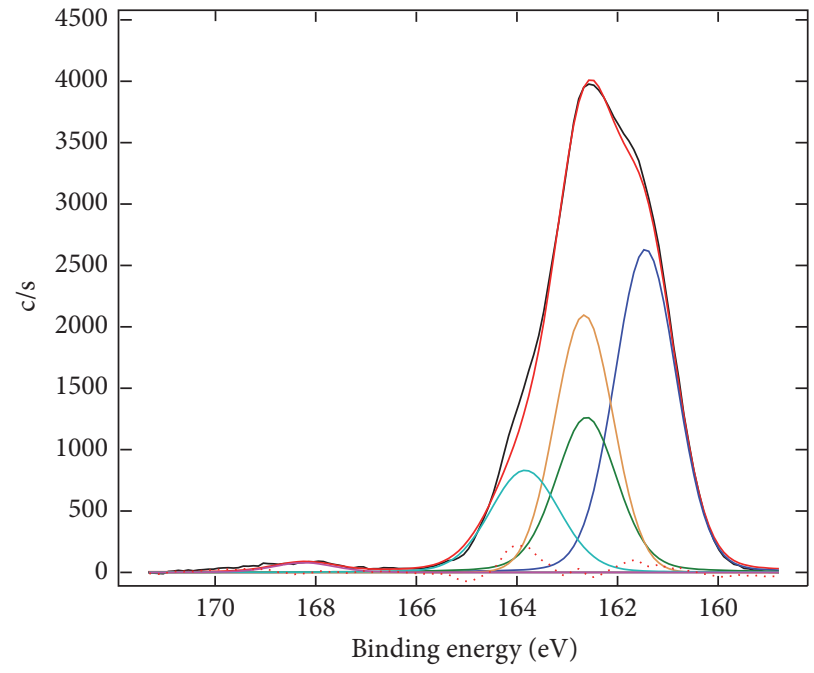

(a)

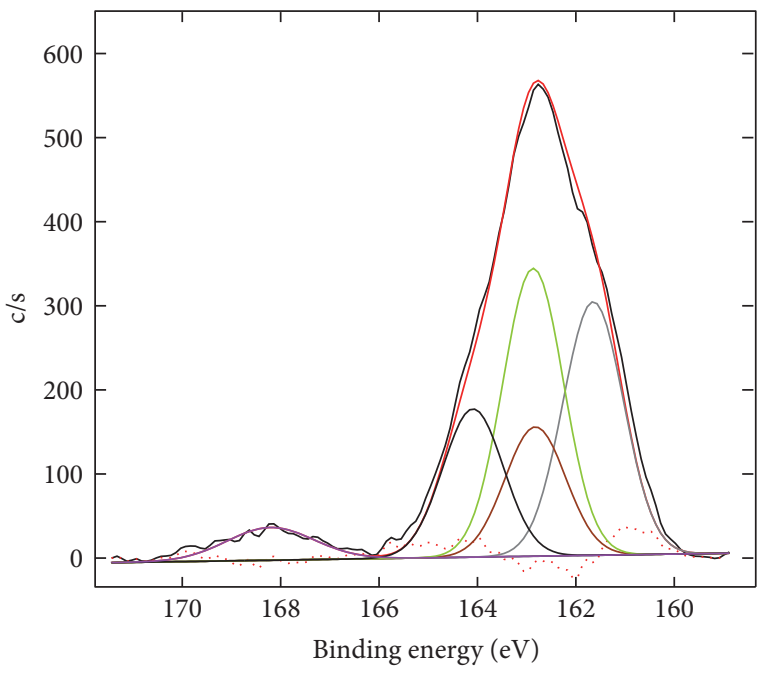

(b)

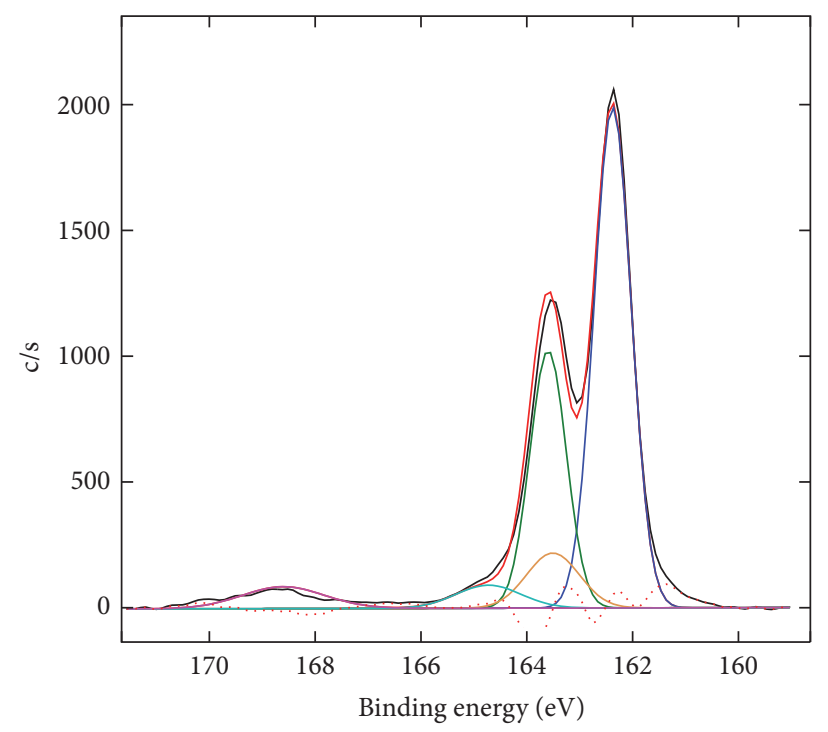

(c)

FIGURE 5: Fitted S2p XPS spectra of $\mathrm{MoS}_{3}$ (a) and $\mathrm{MoS}_{x}-\mathrm{PVP}(0.5)$ before reaction (b) and after reaction (c).

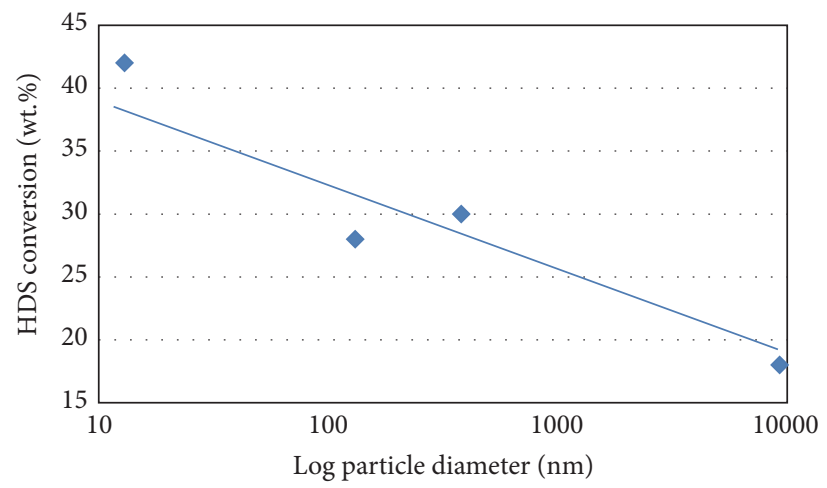

FIGURE 6: Variation of HDS conversion with particle size (logarithmic scale). 
provided through the NSERC/NEXEN/AIEES Industrial Research Chair in Catalysis for Bitumen Upgrading. Also, the contribution of facilities from the Canada Foundation for Innovation, the Institute for Sustainable Energy, Environment and Economy, and the Schulich School of Engineering at the University of Calgary are greatly appreciated. Special thanks are also extended to Dr. Tobias Fürstenhaupt for his help with the Electron Microscopy determinations and Ms. Jodi David for revision of the manuscript.

\section{References}

[1] C. E. Scott and P. Pereira-Almao, "Catalysis for heavy oils and bitumen upgrading," Current Topics in Catalysis, vol. 11, pp. 124, 2014.

[2] M. S. Rana, V. Sámano, J. Ancheyta, and J. A. I. Diaz, "A review of recent advances on process technologies for upgrading of heavy oils and residua," Fuel, vol. 86, no. 9, pp. 1216-1231, 2007.

[3] N. Panariti, A. Del Bianco, G. Del Piero, and M. Marchionna, "Petroleum residue upgrading with dispersed catalysts. Part 1. Catalysts activity and selectivity," Applied Catalysis A: General, vol. 204, no. 2, pp. 203-213, 2000.

[4] N. Panariti, A. Del Bianco, G. Del Piero, M. Marchionna, and P. Carniti, "Petroleum residue upgrading with dispersed catalysts. Part 2. Effect of operating conditions," Applied Catalysis A: General, vol. 204, no. 2, pp. 215-222, 2000.

[5] K. P. Tian, A. R. Mohamed, and S. Bhatia, "Catalytic upgrading of petroleum residual oil by hydrotreating catalysts: a comparison between dispersed and supported catalysts," Fuel, vol. 77, no. 11, pp. 1221-1227, 1998.

[6] B. Demirel and E. N. Givens, "Hydroconversion of resids with dispersed molybdenum catalysts derived from phosphomolybdates," Fuel, vol. 79, no. 15, pp. 1975-1980, 2000.

[7] J. Thompson, A. Vasquez, J. M. Hill, and P. Pereira-Almao, "The synthesis and evaluation of up-scalable molybdenum based ultra dispersed catalysts: effect of temperature on particle size," Catalysis Letters, vol. 123, no. 1-2, pp. 16-23, 2008.

[8] B. Fixari, S. Peureux, J. Elmouchnino, P. Le Perchec, M. Vrinat, and F. Morel, "New developments in deep hydroconversion of heavy oil residues with dispersed catalysts. 1. Effect of metals and experimental conditions," Energy \& Fuels, vol. 8, no. 3, pp. 588-592, 1994.

[9] C. E. Galarraga and P. Pereira-Almao, "Hydrocracking of athabasca bitumen using submicronic multimetallic catalysts at near in-reservoir conditions," Energy and Fuels, vol. 24, no. 4, pp. 2383-2389, 2010.

[10] P. P. Almao, "In situ upgrading of bitumen and heavy oils via nanocatalysis," Canadian Journal of Chemical Engineering, vol. 90, no. 2, pp. 320-329, 2012.

[11] P. Pereira-Almao, Z. Chen, B. Maini, and C. E. Scott, "In situ upgrading via hot fluid injection," Canadian Patent 2,810,022, December 2014.

[12] A. Zamani, B. Maini, and P. Pereira-Almao, "Experimental study on transport of ultra-dispersed catalyst particles in porous media," Energy \& Fuels, vol. 24, no. 9, pp. 4980-4988, 2010.

[13] Y. Kuriki, K. Uchida, E. Sekreta, S. Ohshima, M. Yumura, and F. Ikazaki, "Mechanical milling of metal sulfide particles and their catalytic activity-hydrogenation of 1-methylnaphthalene with molybdenum sulfide," Fuel Processing Technology, vol. 59, no. 23, pp. 189-200, 1999.
[14] D. Astruc, Ed., Nanoparticles and Catalysis, Wiley-VCH, Weinhein, Germany, 2008.

[15] S. Bano, S. W. Ahmad, S. I. Woo, and F. Saleem, "Heavy oil hydroprocessing: effect of nanostructured morphologies of $\mathrm{MoS}_{2}$ as catalyst," Reaction Kinetics, Mechanisms and Catalysis, vol. 114, no. 2, pp. 473-487, 2015.

[16] M. Zdražil, "Recent advances in catalysis over sulphides," Catalysis Today, vol. 3, no. 4, pp. 269-365, 1988.

[17] X. Chen, X. Wang, Z. Wang, W. Yu, and Y. Qian, "Direct sulfidization synthesis of high-quality binary sulfides $\left(\mathrm{WS}_{2}, \mathrm{MoS}_{2}\right.$, and $\mathrm{V}_{5} \mathrm{~S}_{8}$ ) from the respective oxides," Materials Chemistry and Physics, vol. 87, no. 2-3, pp. 327-331, 2004.

[18] P. T. Vasudevan and F. Zhang, "Characterization of supported molybdenum sulfide catalyst ex ammonium tetrathiomolybdate," Applied Catalysis A, General, vol. 112, no. 2, pp. 161-173, 1994.

[19] I. Uzcanga, M. Vrinat, I. Bezverkhyy, P. Afanasiev, and C. E. Scott, "Ultrasound assisted synthesis, in aqueous media, of nanometric $\mathrm{MoS}_{2}$ and its promotion with Co," in Proceedings of the 3rd International Symposium on Hydrotreating/Hydrocracking Technologies, vol. 52, pp. 27-28, Boston, Mass, USA, August 2007.

[20] J. J. Lee, H. Kim, and S. H. Moon, "Preparation of highly loaded, dispersed $\mathrm{MoS}_{2} / \mathrm{Al}_{2} \mathrm{O}_{3}$ catalysts for the deep hydrodesulfurization of dibenzothiophenes," Applied Catalysis B: Environmental, vol. 41, no. 1-2, pp. 171-180, 2003.

[21] I. Uzcanga, I. Bezverkhyy, P. Afanasiev, C. Scott, and M. Vrinat, "Sonochemical preparation of $\mathrm{MoS}_{2}$ in aqueous solution: replication of the cavitation bubbles in an inorganic material morphology," Chemistry of Materials, vol. 17, no. 14, pp. 35753577, 2005.

[22] K. E. Marchand, M. Tarret, J. P. Lechaire, L. Normand, S. Kasztelan, and T. Cseri, "Investigation of AOT-based microemulsions for the controlled synthesis of $\mathrm{MoS}_{x}$ nanoparticles: An Electron Microscopy Study," Colloids and Surfaces A: Physicochemical and Engineering Aspects, vol. 214, no. 1-3, pp. 239-248, 2003.

[23] H. Romero, I. Uzcanga, H. Guzmán et al., "Nanometric NiMo sulfides prepared by thermal decomposition of microemulsions," American Chemical Society, Division of Petroleum Chemistry, vol. 54, pp. 53-55, 2009.

[24] C. Contreras, C. E. Scott, and P. Pereira-Almao, "Preparation of $\mathrm{Ni}, \mathrm{Mo}$, and NiMo nanoparticles from transient w/o emulsions," American Chemical Society, Division of Petroleum Chemistry, vol. 54, pp. 56-58, 2009.

[25] L. Lippolis, H. Guzmán, C. Bolívar, P. Pereira-Almao, and C. E. Scott, "Unsupported NiMoS catalyst prepared from emulsions formed by ultrasonic irradiation," American Chemical Society, Division of Energy and Fuels, vol. 59, pp. 596-598, 2014.

[26] E. Boakye, L. R. Radovic, and K. Osseo-Asare, "Microemulsionmediated synthesis of nanosize molybdenum sulfide particles," Journal of Colloid and Interface Science, vol. 163, no. 1, pp. 120129, 1994

[27] C. E. Scott, M. J. Perez-Zurita, L. A. Carbognani et al., "Preparation of NiMoS nanoparticles for hydrotreating," Catalysis Today, vol. 250, pp. 21-27, 2015.

[28] H. Guzmán, H. Molero, M. J. Pérez-Zurita, P. Pereira-Almao, and C. E. Scott, "Preparation of $\mathrm{MoS}_{x}-\mathrm{AlO}_{x}$ nanoparticles by decomposition of DLH," American Chemical Society, Division of Petroleum Chemistry, vol. 56, pp. 73-75, 2011. 
[29] B. A. Rozenberg and R. Tenne, "Polymer-assisted fabrication of nanoparticles and nanocomposites," Progress in Polymer Science, vol. 33, no. 1, pp. 40-112, 2008.

[30] M. L. Hassan and A. F. Ali, "Synthesis of nanostructured cadmium and zinc sulfides in aqueous solutions of hyperbranched polyethyleneimine," Journal of Crystal Growth, vol. 310, no. 24, pp. 5252-5258, 2008.

[31] B. S. Amma, K. Ramakrishna, and M. Pattabi, "Comparison of various organic stabilizers as capping agents for CdS nanoparticles synthesis," Journal of Materials Science: Materials in Electronics, vol. 18, no. 11, pp. 1109-1113, 2007.

[32] P. Bansal, N. Jaggi, and S. K. Rohilla, "Green synthesis of CdS nanoparticles and effect of capping agent concentration on crystallite size," Research Journal of Chemical Sciences, vol. 2, pp. 69-71, 2012.

[33] R. Tamrakar, M. Ramrakhiani, and B. P. Chandra, "Effect of capping agent concentration on photophysical properties of zinc sulfide nanocrystals," The Open Nanoscience Journal, vol. 2, no. 1, pp. 12-16, 2008.

[34] H. W. Wang, P. Skeldon, G. E. Thompson, and G. C. Wood, "Synthesis of molybdenum disulphide by acidification of ammonium tetrathiomolybdate solutions," Journal of Materials Science Letters, vol. 15, no. 6, pp. 494-496, 1996.

[35] S. Kasztelan, H. Toulhoat, J. Grimblot, and J. P. Bonnelle, "A geometrical model of the active phase of hydrotreating catalysts," Applied Catalysis, vol. 13, no. 1, pp. 127-159, 1984.

[36] S. Eijsbouts, J. J. L. Heinerman, and H. J. W. Elzerman, " $\mathrm{MoS}_{2}$ structures in high activity hydrotreating catalysts. II. Evolution of the active phase during the catalyst life cycle. Deactivation model," Applied Catalysis A: General, vol. 105, no. 1, pp. 69-82, 1993.

[37] P. Afanasiev, G.-F. Xia, G. Berhault, B. Jouguet, and M. Lacroix, "Surfactant-assisted synthesis of highly dispersed molybdenum sulfide," Chemistry of Materials, vol. 11, no. 11, pp. 3216-3219, 1999.

[38] H. W. Wang, P. Skeldon, and G. E. Thompson, "Thermogravimetric-differential thermal analysis of the solid-state decomposition of ammonium tetrathiomolybdate during heating in argon," Journal of Materials Science, vol. 33, no. 12, pp. 30793083, 1998.

[39] K. S. Liang, J. P. deNaufville, A. J. Jacobson, R. R. Chianelli, and F. Betts, "Structure of amorphous transition metal sulfides," Journal of Non-Crystalline Solids, vol. 35-36, no. 2, pp. 12491254, 1980.

[40] K. S. Liang, S. P. Cramer, D. C. Johnston et al., "Amorphous $\mathrm{MoS}_{3}$ and $\mathrm{WS}_{3}$," Journal of Non-Crystalline Solids, vol. 42, no. 1-3, pp. 345-356, 1980.

[41] D. Bélanger, G. Laperrière, F. Girard, D. Guay, and G. Tourillon, "Physicochemical characteristics of electrochemically deposited molybdenum sulfide and polypyrrole-tetrathiomolybdate/molybdenum trisulfide composite electrodes," Chemistry of Materials, vol. 5, no. 6, pp. 861-868, 1993.

[42] T. Weber, J. C. Muijsers, and J. W. Niemantsverdriet, "Structure of amorphous $\mathrm{MoS}_{3}$," Journal of Physical Chemistry, vol. 99, no. 22, pp. 9194-9200, 1995.

[43] G. C. Stevens and T. Edmonds, "Electron spectroscopy for chemical analysis spectra of molybdenum sulfides," Journal of Catalysis, vol. 37, no. 3, pp. 544-547, 1975.

[44] H. W. Wang, P. Skeldon, and G. E. Thompson, "XPS studies of $\mathrm{MoS}_{2}$ formation from ammonium tetrathiomolybdate solutions," Surface and Coatings Technology, vol. 91, no. 3, pp. 200207, 1997.
[45] J. Iranmahboob, S. D. Gardner, H. Toghiani, and D. O. Hill, "XPS study of molybdenum sulfide catalyst exposed to $\mathrm{CO}$ and $\mathrm{H}_{2}$," Journal of Colloid and Interface Science, vol. 270, no. 1, pp. 123126, 2004.

[46] H. Vrubel, D. Merki, and X. Hu, "Hydrogen evolution catalyzed by $\mathrm{MoS}_{3}$ and $\mathrm{MoS}_{2}$ particles," Energy \& Environmental Science, vol. 5, no. 3, pp. 6136-6144, 2012.

[47] G. F. Khudorozhko, I. P. Asanov, L. N. Mazalov et al., "The study of electronic structure of molybdenum and tungsten trisulfides and their lithium intercalates by $\mathrm{x}$-ray electron and $\mathrm{x}$ ray emission and absorption spectroscopy," Journal of Electron Spectroscopy and Related Phenomena, vol. 68, pp. 199-209, 1994.

[48] T. K. T. Ninh, L. Massin, D. Laurenti, and M. Vrinat, "A new approach in the evaluation of the support effect for NiMo hydrodesulfurization catalysts," Applied Catalysis A: General, vol. 407, no. 1-2, pp. 29-39, 2011. 

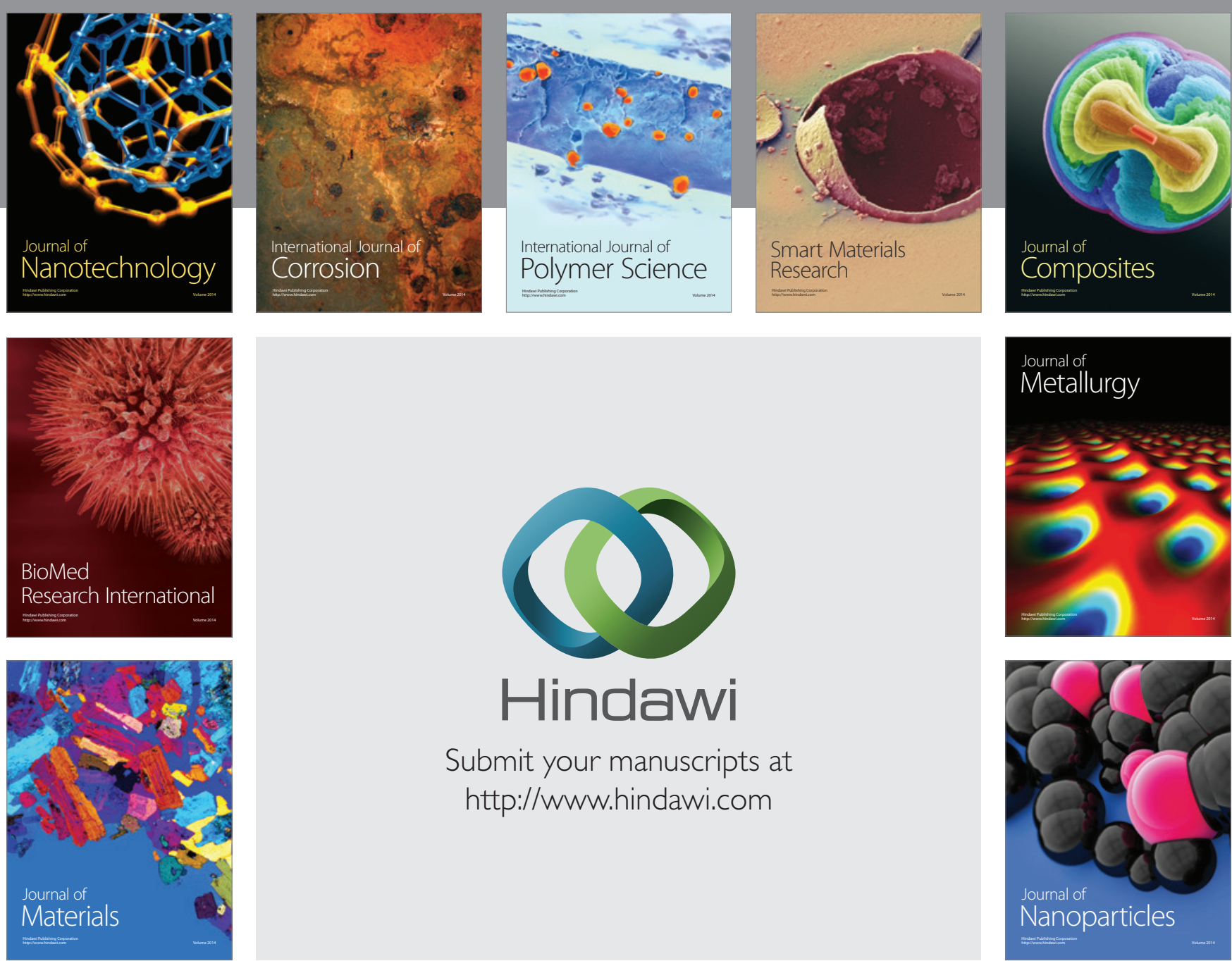

\section{Hindawi}

Submit your manuscripts at

http://www.hindawi.com

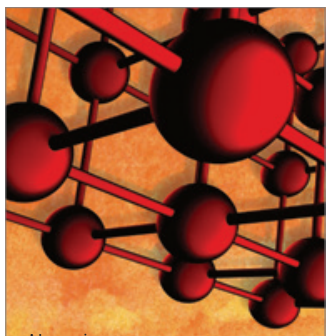

Materials Science and Engineering
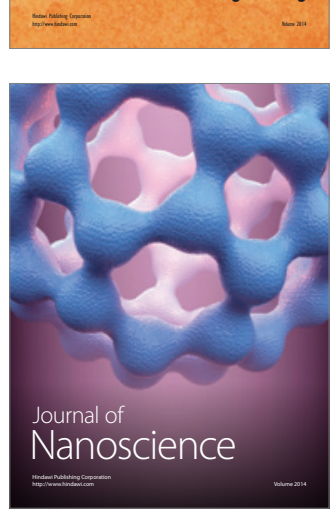
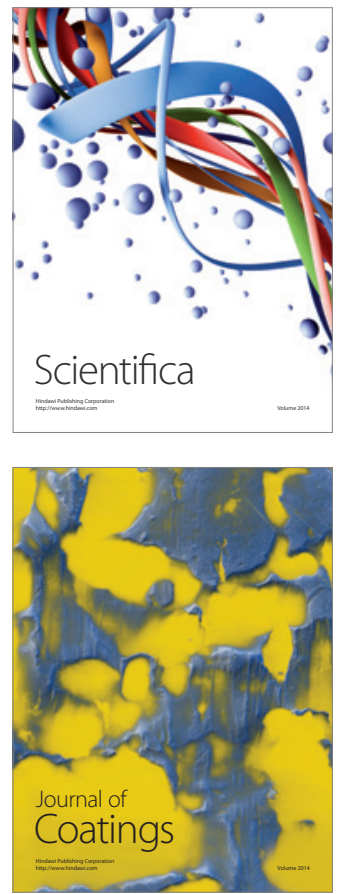
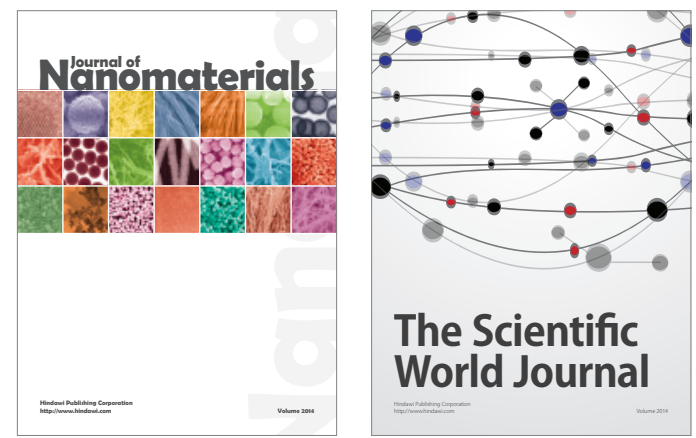

The Scientific World Journal
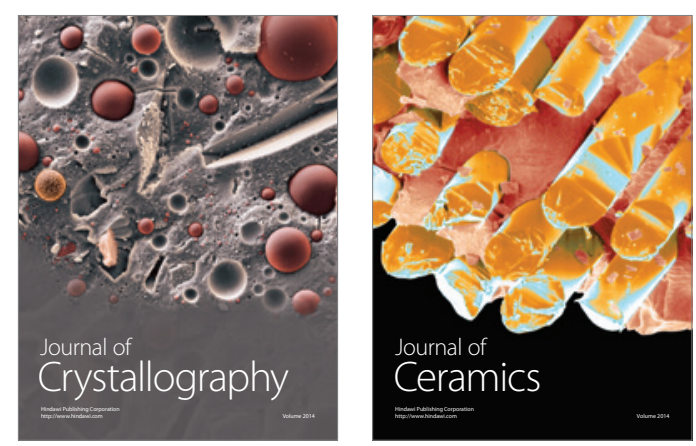
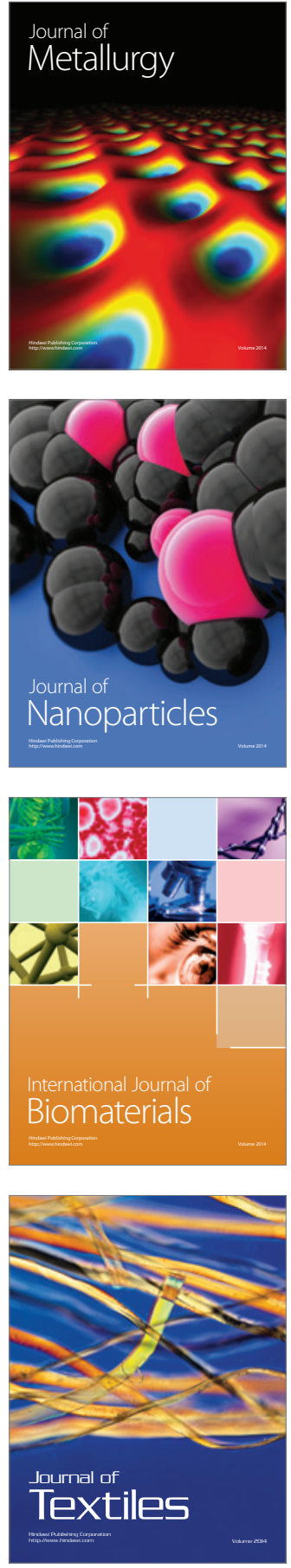